\title{
Long-term community-based monitoring of tamaraw Bubalus mindorensis on Mindoro Island, Philippines
}

\author{
Shinya Ishinara, Rodel M. Boyles, Hisashi Matsubayashi \\ Arnel N. del Barrio, Merben R. Cebrian, Aiko Ishida, Rosalina M. Lapitan \\ Eufrocina P. Atabay, Libertado C. Cruz and Yukio Kanai
}

\begin{abstract}
The Critically Endangered tamaraw Bubalus mindorensis is endemic to Mindoro Island, Philippines, and little is known of its ecology. During 2006-2011 we used community-based monitoring to examine the population status and ecology of tamaraw in the species' core habitat of Mount Iglit-Baco National Park. Each year, for 5 consecutive days at the end of the dry season, trained local volunteers and rangers or project staff were allocated to 18 vantage points in the study area $\left(\mathrm{c} .160 \mathrm{~km}^{2}\right)$. Tamaraw were categorized as adult ( $>5$ years), juvenile ( $2-5$ years) or calf $(<2$ years), and sexed when possible. During the study period the population was 239-314 (mean 271), with no significant fluctuations in age structure (percentage of adults, juveniles and calves: $57.8,21.0$ and 21.3\%) or estimated adult female reproductive rates (29.1\%). In adults, but not in juveniles, the sex ratio was biased towards females $(1: 1.86, \mathrm{P}<0.01)$. Bulls were often solitary $(32.2 \%$ of sightings), whereas the majority of cows ( $94.7 \%)$ formed small groups of 2-12 individuals of different ages, with or without bulls ( 53.4 and $46.6 \%$, respectively). These results demonstrate that the population remained relatively stable, maintaining a constant age structure and reproductive rate, and that long-term community-based monitoring was
\end{abstract}

SHINYA IsHIHARA* and YUKIO KANAI (Corresponding author) Graduate School of Life and Environmental Sciences, University of Tsukuba, Tsukuba, Ibaraki 305-8572, Japan. E-mail montay@jcom.home.ne.jp

Rodel M. Boyles* Tamaraw Conservation Programme, Department of Environment and Natural Resources, San Jose, Occidental Mindoro, Philippines

Hisashi Matsubayashi $\dagger$ Institute for Tropical Biology and Conservation, Universiti Malaysia Sabah, Kota Kinabalu, Sabah, Malaysia

Arnel N. Del Barrio and Rosalina M. Lapitan Philippine Carabao Center, University of the Philippines at Los Baños, Laguna, Philippines

Merben R. CEbrian USDOI Bureau of Land Management, Fairbanks, Alaska, USA

AIKO IsHIDA National Institute of Livestock and Grassland Science, Tsukuba, Ibaraki, Japan

Eufrocina P. Atabay and Libertado C. Cruz Philippine Carabao Center, National Headquarters, Munoz, Nueva Ecija, Philippines

* The first two authors contributed equally to this work.

$\dagger$ Current address: Department of Forest Science, Tokyo University of Agriculture, Setagaya, Tokyo, Japan

Received 11 December 2012. Revision requested 7 June 2013.

Accepted 29 April 2014. First published online 1 August 2014. effective for quantitative characterization of the tamaraw's social behaviour, which is critical for conservation and management of the species.

Keywords Bubalus mindorensis, community-based monitoring, Critically Endangered species, Mindoro Island, population trend, tamaraw

\section{Introduction}

The Philippine archipelago comprises a land area of L. $300,000 \mathrm{~km}^{2}$ and hosts 206 native species of land mammals. It is a biodiversity hotspot but 117 (57\%) of the endemic native land mammals are threatened by habitat loss, illegal hunting and human encroachment (Myers et al., 2000). The tamaraw Bubalus mindorensis, which is endemic to the island of Mindoro, is categorized as Critically Endangered on the IUCN Red List (Hedges et al., 2008). It is believed that tamaraw were once distributed throughout the island, coexisting with the indigenous Mangyan people, who traditionally practised slash-and-burn agriculture (Everett, 1878; Steere, 1888). However, the tamaraw population decreased during the early 20 th century as a result of increased human activity, particularly hunting (Manuel, 1957; Harrisson, 1969), and is currently estimated to be c. 300. Its distribution is restricted to three protected areas (Mount Iglit-Baco National Park, Mount Aruyan-Malati Tamaraw Reservation and Mount Calavite Wildlife Sanctuary), with $>90 \%$ of individuals belonging to the sub-population of Mount Iglit-Baco National Park (Hedges et al., 2008).

Information on population status is essential for wildlife conservation and management (Primack, 1993), and an understanding of ecological traits such as social behaviours, mating systems and habitat selection is necessary to design a successful wildlife conservation programme (Curio, 1996; Caro, 1999; Anthony \& Blumstein, 2000). However, for Critically Endangered species, particularly in tropical countries, such information is not widely available in the scientific literature (Collen et al., 2008). Some studies have examined the physiological or cytogenetic traits of tamaraw in captivity but little is known about the ecology of tamaraw in the wild (Maala, 2001). 
The scarcity of data from tropical countries is attributed to inappropriate resource allocation (Sheil, 2001) or insufficient funding and lack of adequate infrastructure and expertise for data collection (Collen et al., 2008). To address this situation it has been suggested that monitoring of threatened species may benefit from a participatory approach (Danielsen et al., 2009) and that local communitybased monitoring can be as reliable as professional monitoring if it is performed with attention to objectives, methodological designs and intensive analyses (Burton, 2012).

In 1999 the Department of Environment and Natural Resources of the Philippines shifted the priority of its Tamaraw Conservation Programme from captive breeding to the protection of wild populations in Mount Iglit-Baco National Park in accordance with the recommendations of the Population and Habitat Viability Assessment for Tamaraw (IUCN/SSC Conservation Breeding Specialist Group, 1996). The Tamaraw Conservation Programme is linked with the Community Assistance Programme, which is a livelihood assistance programme for local communities within or near tamaraw habitats, and the nationwide Information, Education and Communication Campaign, which aims to educate people, organize local partnerships and develop local biodiversity conservation. A large-scale community-based monitoring programme, the Tamaraw Population Count, was initiated to determine the number of tamaraw in the core habitat in Mount Iglit-Baco National Park (Philippine Clearing House Mechanism, 2012) and this has become a regular annual activity since 2000, providing realistic estimates of the tamaraw population in the Park (Department of Environment and Natural Resources Region 4B, 2012). This suggests that community-based tamaraw monitoring can generate relevant ecological data and population estimates, with only minor modifications in data collection and analysis procedures.

Our objective was to use community-based monitoring to improve our understanding of tamaraw ecology in the wild. Data on the ecology of tamaraw were collected in the Mount Iglit range over 6 years and were used to estimate population size, age structure, reproductive rates of adult females and social behaviours. Data on the prevalence of endoparasites were also collected, to evaluate the general health of wild tamaraw.

\section{Study area}

Mount Iglit-Baco National Park $\left(754 \mathrm{~km}^{2}\right)$ is located in central Mindoro Island (Fig. 1). It has a tropical monsoon climate, with dry (December-May) and wet (JuneNovember) seasons. The tamaraw conservation area in the Park is c. $160 \mathrm{~km}^{2}$ and comprises hilly terrain at altitudes of
300-1,000 m. High-altitude areas are dominated by perennial grasses such as cogon Imperata cylindrica, talahib Saccharum spontaneum and themeda Themeda triandra, whereas low-altitude areas are characterized by grassland, with patches of secondary forest and bamboo; the vegetation along rivers is sufficiently dense to provide cover for tamaraw (Maala, 2001; Cebrian et al., 2014). The Philippine deer Rusa marianna and Oliver's warty pig Sus oliveri have also been observed in the area but no tamaraw predators have been reported.

\section{Methods}

Participants in the Tamaraw Population Count included schoolteachers, public workers, NGOs and local government employees. Prior to the field surveys these volunteer observers (20-30 people) were trained in survey methods, including protocols for counting, identification of age and sex, and use of binoculars, maps and compasses. They were allocated to one of 18 vantage points in the tamaraw conservation area, where at least one ranger or project staff member was concurrently assigned, to minimize possible counting errors. There were c. 50 observers in total.

Tamaraw were counted simultaneously at the 18 vantage points each April during 2006-2011 (IUCN/SSC Conservation Breeding Specialist Group, 1996; Fig. 1c). Observers were equipped with compasses and binoculars and/or spotting scopes. Controlled burning of grass was carried out 1-2 months before the count, to facilitate visibility and to entice tamaraw into the open with an abundance of emerging sprouts and young grasses; burning reduced the total grass biomass temporarily but increased the ratio of the edible portion of grasses and its crude protein content significantly at the time of the tamaraw count (R. Lapitan et al., unpubl. data). To minimize disturbance to the tamaraw burning was limited to the main grasslands and was carefully controlled to prevent the fire from spreading to forest edges or river basins, which tamaraw use as resting places and travel corridors.

Observations were made simultaneously at all vantage points for 5 consecutive days (22-26 April) at 05.30-07.00 and 17.00-18.30, when tamaraw generally graze (Momongan $\&$ Walde, 1993). For each sighting the time and the direction and distance of the tamaraw from the observation site were recorded. When groups of tamaraw were sighted, group size and composition were recorded.

Tamaraw were categorized as adults $(>5$ years, sexually mature), juveniles (2-5 years) or calves ( $<2$ years), according to previous studies (Kuehn, 1986; Ong et al., 1996), based on body conformation, fur colour and horn size: calves, reddish brown or light brown fur, no horns or horns not reaching the ear tips; juveniles, obvious black 


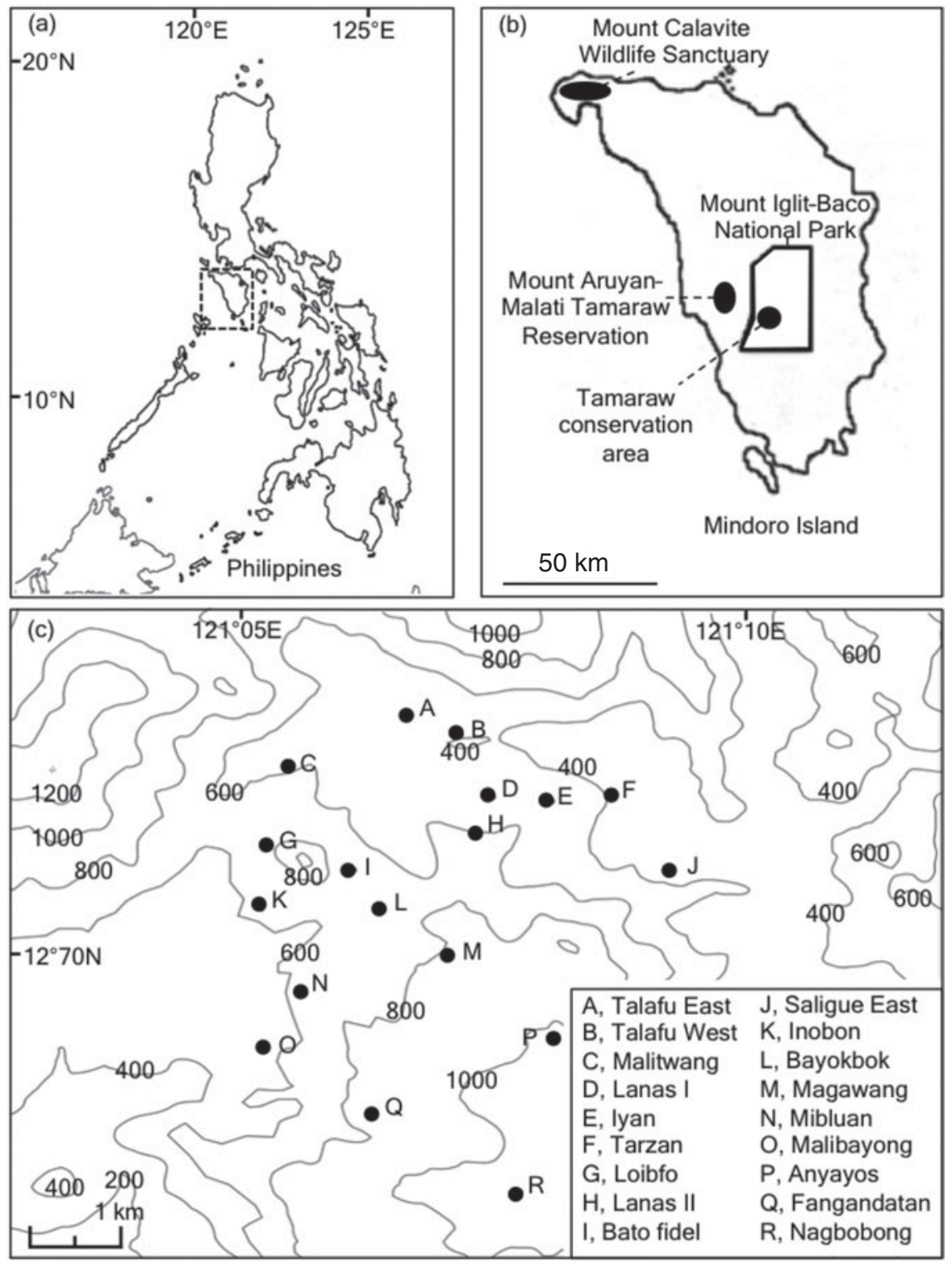

FIG. 1 (a) Location of Mindoro Island in the Philippines, (b) habitat ranges of tamaraw Bubalus mindorensis on the island, and (c) topography of the tamaraw conservation area (c. $160 \mathrm{~km}^{2}$ ) in Mount Iglit-Baco National Park (754 $\mathrm{km}^{2}$ ), and locations of the 18 vantage points used in the survey. Tamaraw have been confirmed in three protected areas on Mindoro, with $>90 \%$ of individuals inhabiting the tamaraw conservation area. dorsal stripe, spike-like horns extending beyond ear tips; adults, brown to greyish-black fur with pale dorsal stripes, $\mathrm{v}$-shaped horns extending over the head.

The sex of adult or juvenile tamaraw was determined based on body conformation, horn shape and genitalia when visible. Adult males have wider and thicker horns than females and are more muscular. When it was difficult or impossible to determine the sex of individuals they were categorized as sex-unidentified.

The prevalence of endoparasites was investigated as an indicator of tamaraw health status. Fresh faecal samples from tamaraw were collected in the vicinity of observation sites and stored in $10 \%$ formalin. Subsequently, endoparasite eggs were detected using a sedimentation method (Hendrix, 1998).

Data from each observation site were consolidated during a workshop after the 5-day field survey each year and any possible double or multiple counts from two or more observation sites were removed. The sex ratios among adults and juveniles were calculated, excluding sexunidentified animals. The reproductive rate of adult females was estimated from the ratio between the number of calves $<_{1}$ year old and the number of adult females. In this estimation half of the animals categorized as calves were assumed to be $<1$ year old and half of the sex-unidentified adults were assumed to be females and were included in the total adult female population.

Binomial tests were used to determine whether observed sex ratios differed from the expected sex ratio of $1: 1$. We used $\chi^{2}$ tests to determine whether the distribution of categorical variables such as gender and age were independent of the year. Statistical differences between means were examined using a Student's $t$-test. Differences were considered significant when $\mathrm{P}<0.05$. 


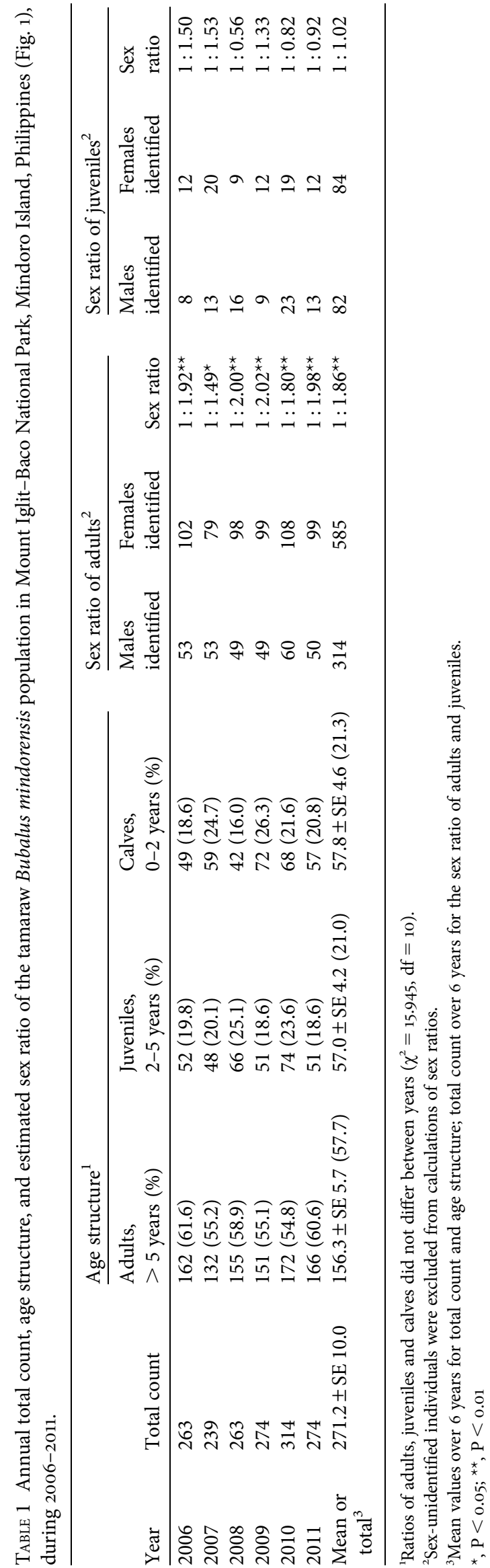

TABLE 2 Estimation of reproductive rates among adult females in the tamaraw population in Mount Iglit-Baco National Park (Fig. 1) during 2006-2011.

\begin{tabular}{llll}
\hline Year & $\begin{array}{l}\text { No. of adult } \\
\text { females }^{1}\end{array}$ & $\begin{array}{l}\text { No. of calves } \\
<1 \text { year old }\end{array}$ & $\begin{array}{l}\text { Estimated adult } \\
\text { female reproductive } \\
\text { rate }^{3}(\%)\end{array}$ \\
\hline 2006 & 105.5 & 24.5 & 23.2 \\
2007 & 79 & 29.5 & 37.3 \\
2008 & 102 & 21 & 20.6 \\
2009 & 100.5 & 36 & 35.8 \\
2010 & 110 & 34 & 30.9 \\
2011 & 107.5 & 28.5 & 26.5 \\
Mean & $100.8 \pm$ SE 4.6 & $28.9 \pm$ SE 2.3 & $29.1 \pm$ SE 2.8 \\
\hline
\end{tabular}

${ }^{1}$ Half of sex-unidentified adult animals were considered female and included in adult female population count.

${ }^{2} \mathrm{Half}$ of animals identified as calves in Table 1 were assumed to be $<1$ year old.

${ }^{3}$ Estimated adult female reproductive rates did not differ by year $\left(\chi^{2}=5.923\right.$, $\mathrm{df}=5)$.

\section{Results}

The number of tamaraw counted during each year of the study was 239-314 (mean 271), with a small fluctuation (coefficient of variation 0.09) over the 6 years (Table 1). On average, the percentages of adults, juveniles and calves were $57.7,21.0$ and $21.3 \%$, respectively. The age structure did not differ from year to year but the number of juveniles per 1 year of age was significantly lower than that of calves over the 6-year period (19.0 \pm SE 1.4 vs $28.9 \pm$ SE 2.3; Student's $t$-test, $\mathrm{P}<0.05)$.

Sex identification was possible for $96 \%$ of adults and $49 \%$ of juveniles (Table 1). The sex ratio of adults was consistently biased towards females (overall adult male: female ratio $=1: 1.86$; binomial test, $z=9.038, \mathrm{P}<0.01$ ) but no bias was observed among juveniles. Reproductive rates among adult females were 20.6-37.3\% (mean 29.1\%), and did not differ significantly between years (Table 2).

Of the 1,627 tamaraw counted, 10\% were alone and 90\% were in groups (Table 3). Although there was a consistent tendency towards group formation, the proportion of solitary animals varied annually $\left(\chi^{2}=20.453, \mathrm{df}=5\right.$, $\mathrm{P}<0.01)$. Of the 163 solitary animals $101(61.9 \%)$ were adult males, 31 (19.0\%) were adult females, nine (5.5\%) were sex-unidentified adults, and others included 19 juveniles and three calves. Groups comprised 2-12 individuals (overall mean of 3.57 ); the majority of the groups (88.9\%) comprised 2-5 individuals.

Most groups included one or two adult females (358/ $378,94.7 \%)$ and approximately half of the groups (200/378, $52.9 \%$ ) were accompanied by an adult bull (Table 4 ). Tamaraw in groups stayed within c. $10 \mathrm{~m}$ of each other and almost all groups remained in the same location during 5 consecutive days of observation. They were often observed 
TABle 3 The number of tamaraw observed alone or in groups in Mount Iglit-Baco National Park (Fig. 1) during $2006-2011$.

\begin{tabular}{|c|c|c|c|c|c|c|c|c|c|c|c|c|}
\hline \multirow[b]{2}{*}{ Year } & \multirow{2}{*}{$\begin{array}{l}\text { No. of solitary } \\
\text { tamaraw }(\%)\end{array}$} & \multirow{2}{*}{$\begin{array}{l}\text { No. of tamaraw in } \\
\text { groups }^{*}(\%)\end{array}$} & \multirow{2}{*}{$\begin{array}{l}\text { Total no. of } \\
\text { groups }\end{array}$} & \multirow{2}{*}{$\begin{array}{l}\text { Mean group } \\
\text { size }\end{array}$} & \multicolumn{8}{|c|}{ No. of groups of 2-12 tamaraw } \\
\hline & & & & & 2 & 3 & 4 & 5 & 6 & 7 & 8 & 12 \\
\hline 2006 & $29(11.0)$ & $234(89.0)$ & 71 & 3.30 & 23 & 21 & 17 & 6 & 1 & 3 & 0 & 0 \\
\hline 2007 & $12(5.0)$ & $227(95.0)$ & 59 & 3.85 & 12 & 13 & 16 & 12 & 2 & 4 & 0 & 0 \\
\hline 2008 & $19(7.0)$ & $244(93.0)$ & 62 & 3.94 & 14 & 15 & 12 & 10 & 5 & 5 & 1 & 0 \\
\hline 2009 & $26(9.5)$ & $248(90.5)$ & 72 & 3.44 & 24 & 22 & 10 & 7 & 5 & 3 & 1 & 0 \\
\hline 2010 & $33(10.5)$ & $281(89.5)$ & 73 & 3.85 & 21 & 19 & 11 & 7 & 8 & 5 & 1 & 1 \\
\hline 2011 & $44(16.1)$ & $230(83.9)$ & 76 & 3.03 & 31 & 23 & 13 & 8 & 0 & 1 & 0 & 0 \\
\hline Overall & $163(10.0)$ & $1,464(90.0)$ & 413 & 3.57 & 125 & 113 & 79 & 50 & 21 & 21 & 3 & 1 \\
\hline
\end{tabular}

${ }^{*}$ Ratios of solitary animals and non-solitary animals differed significantly by year $\left(\chi^{2}=20.453, \mathrm{df}=5, \mathrm{P}<0.01\right)$.

TABLE 4 Composition of tamaraw groups in terms of numbers of adult males and females. ${ }^{\star}$

\begin{tabular}{llclc}
\hline No. of adult & \multicolumn{2}{l}{ No. of adult males in a group } & & \\
\cline { 2 - 5 } females in a group & 0 & 1 & $1(0.3 \%)$ & Overall \\
\hline 1 & $124(32.8 \%)$ & $109(28.8 \%)$ & $1(0.3 \%)$ & $234(61.9 \%)$ \\
2 & $45(11.9 \%)$ & $78(20.6 \%)$ & $0(0.0 \%)$ & $124(32.8 \%)$ \\
$3-4$ & $7(1.9 \%)$ & $13(3.4 \%)$ & $2(0.5 \%)$ & $20(5.3 \%)$ \\
Overall & $176(46.6 \%)$ & $200(52.9 \%)$ & $378(100.0 \%)$ \\
\hline
\end{tabular}

${ }^{\star}$ Groups lacking an identified adult female are excluded (35 of 413 in Table 3 ).

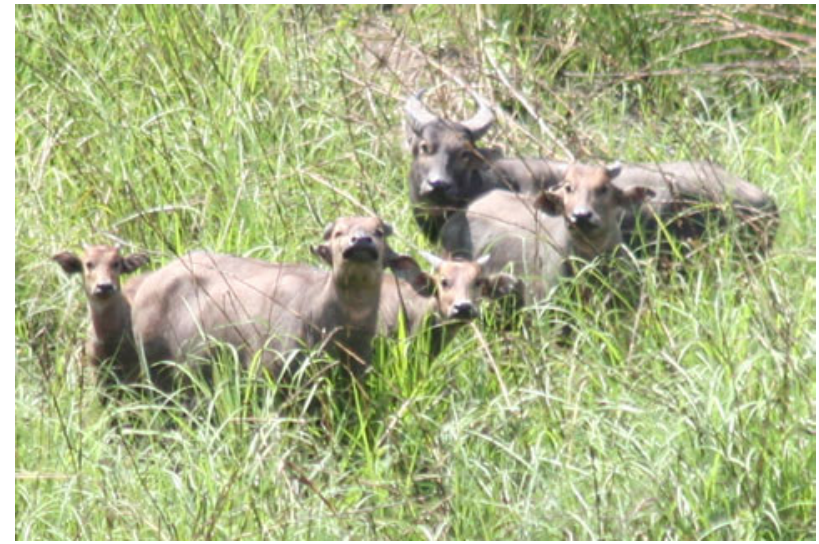

Plate 1 A typical tamaraw Bubalus mindorensis herd comprising one adult male (upper middle), two adult females (1st right and 2nd from the left), one juvenile (lower middle) and one yearling (1st left), near the Loibfo vantage point in 2007 (photographed by Hisashi Matsubayashi).

emerging from the forest or creek areas onto the grassland at sunset and were hidden in forested areas or in tall grasses soon after sunrise. Plate 1 shows a typical tamaraw group comprising five individuals.

Two cases of intense fighting between bulls were witnessed during the study. In the first case the defeated bull suffered a serious injury and in the second case the defeated bull fell over a cliff. In addition, the carcass of a young bull was detected near the Magawang vantage point in 2011, in which a clear puncture wound apparently sustained in a fight was observed on the neck.
Endoparasites were detected in six of $27(22 \%)$ fresh faecal samples but there were no superinfections. The genera were Fasciola $(\mathrm{n}=2)$, Eimeria $(\mathrm{n}=2)$, Strongylus $(\mathrm{n}=1)$ and Ascaris $(\mathrm{n}=1)$.

\section{Discussion}

\section{Population trends and general ecology}

Total counts and annual fluctuations were similar to those recorded during 2002-2005 (Department of Environment and Natural Resources Region 4B, 2012). Our results indicate a stable tamaraw population in Mount Iglit-Baco National Park and sustained precision in community-based tamaraw counting by the Tamaraw Conservation Programme. However, the total counting method generally provides a minimum live estimate because it is unlikely that all individuals will be observed (WWF, 2004), particularly given the tamaraw's nocturnal grazing patterns (Kuehn, 1986). Moreover, animals entering and leaving the study area cannot be ruled out because the area is not a closed system, and therefore a larger study area could result in a higher population estimate, although there is currently no evidence that tamaraw live outside the study area.

Age structure and estimated reproductive rates of adult females did not vary significantly between years, suggesting that the incidence of births and deaths was balanced. Our estimates did not account for calf mortality or that calves may have been concealed in the undergrowth, and therefore 
reproductive rates could be higher than estimated. The estimated calf: cow ratio (0.29) was lower than that reported for closely related species, such as African buffalo Syncerus caffer (0.70; Sinclair, 1977), American bison Bison bison (0.62; Van Vuren \& Bray, 1986) and wild gaur Bos gaurus (0.34; Ahrestani et al., 2011), but similar to that reported for wild water buffalo Bubalus arnee in Nepal (0.29; Heinen, 1993), in which a decline in the calf: cow ratio has been reported (Khatri et al., 2012). As female reproductive rates are a key parameter of population viability, further investigation is required to determine whether the reproductive rates recorded by the monitoring are within the intrinsic performance range of this species or are suppressed by threats in the environment, such as nutrient deficiency as a result of habitat loss.

The lower abundance of juveniles per 1 year of age than of calves suggests that calf mortality is probably high, as reported for other ungulate species (Spinage, 1972). Tamaraw have no obvious predators, and therefore we could assume that shortage of food or resultant malnutrition were the main cause of death. However, most animals had good body conformation and levels of endoparasitic infection were lower than those observed in captive tamaraw (Anunciado et al., 1994). Malnutrition and endoparasitic load are therefore less likely to be major causes of tamaraw mortality, at least in the dry season. However, it is necessary to examine the health status of tamaraw further because endoparasitic infections are generally more prevalent during the wet season (Fritsche et al., 1993; Kuchai et al., 2011) and little is known about habitat use by tamaraw.

The female-biased adult sex ratio observed here is in agreement with observations in other sexually dimorphic ungulate species (African buffalo: Sinclair, 1977; kudu Tragelaphus strepsiceros: Owen-Smith, 1993), among which adult males are believed to suffer higher mortality than females because of higher growth rates, intense intra-male competition and solitary habits (Emlen \& Oring, 1977; Berger \& Gompper, 1999). Observations of intense fights between bulls and the carcass of a young bull with a neck wound suggest that such reasoning may also apply to tamaraw.

Tamaraw are often described as solitary (Talbot \& Talbot, 1966; Kuehn, 1976; Suchomel, 2005). Following 221 days of observation across the wet and dry seasons Kuehn (1986) reported that $82 \%(179 / 218)$ of bulls were solitary individuals and $66 \%(71 / 107)$ of cows were alone or with calves. By contrast, here we observed that $32 \%(101 / 314)$ of bulls were solitary and $95 \%(554 / 585)$ of cows were in small family groups. Social segregation of adult males and females is often observed during the non-breeding season in many ungulate species of temperate regions (Ruckstuhl \& Neuhaus, 2002). However, some tropical ungulate species, such as the African buffalo, adopt periodical segregation throughout the extended breeding season (Turner et al., 2005). Because the tamaraw breeding season and social system are poorly known we cannot infer sexual segregation from our study.

\section{Efficacy of community-based tamaraw monitoring}

Local community-based monitoring is expected to elucidate the status of species and habitats in tropical countries where professional monitoring may be difficult or ineffective, but the reliability of the data collected has been questioned (Danielsen et al., 2005). The accuracy and precision of such monitoring programmes vary according to relative contributions from local stakeholders and professional researchers: larger contributions from local people have resulted in lower reliability but empowered local communities to manage their resources more effectively (Danielsen et al., 2009). Local community-based monitoring has underestimated the size of mammalian communities but has provided reliable population estimates, similar to those of professional monitoring, for large ungulates (Burton, 2012). Knowledge of the strengths and weaknesses of participatory approaches can be used to maximize the potential of community-based monitoring. The small variations in total counts and age-sex structures recorded here are probably attributable to the well-prepared counting procedures, such as the allocation of skilled staff in addition to local volunteers at each observation site, and execution of scheduled burning to facilitate sightings, although the latter may have influenced habitat use by tamaraw to some extent.

Human activities, particularly hunting and exploitation, have the greatest effect on the population dynamics of wild animals (Redford, 1992; Mace \& Reynolds, 2001). The Philippine government prohibited the hunting of tamaraw as early as 1936 but poaching did not stop completely. A field survey in the Mount Aruyan-Malati Tamaraw Reservation revealed that few tamaraw remain there, and they are threatened by poaching and land-use conflicts with the Mangyan people (Matsubayashi et al., 2010). A similar field survey at Mount Calavite Wildlife Sanctuary in 2010 failed to find evidence of the presence of tamaraw (S. Ishihara et al., unpubl. data). Despite the critical situation in these two areas, which had been regarded as potential tamaraw habitats, the tamaraw population appears to be stable in the Mount Iglit range of Mount Iglit-Baco National Park. In addition to population counting, community-based conservation activities such as the Community Assistance Programme and the Information, Education and Communication Campaign may deter poaching and safeguard against habitat destruction and human-tamaraw conflict. Our results indicate a need for continued protection of tamaraw habitat in Mount IglitBaco National Park, continued community-based monitoring, more research into tamaraw ecology and increased 
public awareness and participation in tamaraw conservation.

\section{Acknowledgements}

Our study protocols and collection of field samples in Mount Iglit-Baco National Park were approved by the Memorandum of Agreement between the Department of Environment and Natural Resources and the Department of Agriculture-Philippine Carabao Centre in 2006. We thank the Regional Office of IV-B of the Department of Environment and Natural Resources for signing this Memorandum, Josefina L. de Leon from the Protected Areas and Wildlife Bureau for her advice on the planning of this study, Danilo Z. Rocca (Tamaraw Conservation Programme Field Operation Assistant), Tamaraw Conservation Programme rangers and all the volunteer observers for their perseverance in collecting data, Reynor A. Garcia, Jose C. Canaria and Noel A. Ceballos from the Philippine Carabao Center for grass and faecal sampling, and Professor Atsushi Tajima of the University of Tsukuba for his comments on this article. This study was supported in part by a Grant-in-Aid for Scientific Research (No. 17405040, 09J00274) from the Japan Society for Promotion of Science.

\section{References}

Ahrestani, F.S., Iyer, S., Heit könig, I.M.A. \& Prins, H.H.T. (2011) Life-history traits of gaur Bos gaurus: a first analysis. Mammal Review, 41, 75-84.

Anthony, L.L. \& Blumstein, D.T. (2000) Integrating behaviour into wildlife conservation: the multiple ways that behaviour can reduce $N_{\mathrm{e}}$. Biological Conservation, 95, 303-315.

Anunciado, R.V.P., Eduardo, S.L., Momongan, V.G. \& EsCALADA, R.F. (1994) Parasites of the captive tamaraw, Bubalus mindorensis (Heude, 1988) (Mammalia: Ruminantia). Philippine Journal of Veterinary Medicine, 31, 5-10.

Berger, J. \& Gompper, M.E. (1999) Sex ratios in extant ungulates: products of contemporary predation or past life histories? Journal of Mammalogy, 80, 1084-1113.

Burton, A.C. (2012) Critical evaluation of a long-term, locally-based wildlife monitoring program in West Africa. Biodiversity and Conservation, 21, 3079-3094.

Caro, T. (1999) The behaviour-conservation interface. Trends in Ecology \& Evolution, 14, 366-369.

Cebrian, M.R., Boyles, R.M., De Leon, J.L. \& Burton, J. (2014) Tamaraw. In Ecology, Evolution and Behaviour of Wild Cattle: Implications for Conservation (eds M. Melletti \& J. Burton), pp. 310-317. Cambridge University Press, Cambridge, UK.

Collen, B., Ram, M., Zamin, T. \& McRae, L. (2008) The tropical biodiversity data gap: addressing disparity in global monitoring. Tropical Conservation Science, 1, 75-88.

Curio, E. (1996) Conservation needs ethology. Trends in Ecology \& Evolution, 11, 260-263.

Danielsen, F., Burgess, N.D. \& Balmford, A. (2005) Monitoring matters: examining the potential of locally-based approaches. Biodiversity and Conservation, 14, 2507-2542.
Danielsen, F., Burgess, N.D., Balmford, A., Donald, P.F. Funder, M., Jones, J.P. et al. (2009) Local participation in natural resource monitoring: a characterization of approaches. Conservation Biology, 23, 31-42.

Department of Environment and Natural Resources Region 4B (MIMAROPA) (2012) Tamaraw Population Counting. Http:// mimaropa.denr.gov.ph/index.php/tamaraw-population-counting [accessed 2 April 2014].

Emlen, S.T. \& Oring, L.W. (1977) Ecology, sexual selection, and the evolution of mating systems. Science, 197, 215-223.

Everett, A.H. (1878) Mr. A.H. Everett on Anoa depressicornis. Proceedings of the Zoological Society of London, 5, 792.

Fritsche, T., Kaufmann, J. \& Pfister, K. (1993) Parasite spectrum and seasonal epidemiology of gastrointestinal nematodes of small ruminants in The Gambia. Veterinary Parasitology, 49, 271-283.

Harrisson, T. (1969) The tamaraw and its survival. IUCN Bulletin (New Series), 2, 85-86.

Hedges, S., Duckworth, J.W., de Leon, J., Custodio, C. \& Gonzales, J.C. (2008) Bubalus mindorensis. In IUCN Red List of Threatened Species v. 2011.1. Http://www.iucnredlist.org/details/3127/ o [accessed 2 April 2014].

Heinen, J.T. (1993) Population viability and management recommendations for wild water buffalo Bubalus bubalis in Kosi Tappu Wildlife Reserve, Nepal. Biological Conservation, 65, 29-34.

Hendrix, C.M. (1998) Diagnostic Veterinary Parasitology, 2nd edition. Mosby, St. Louis, USA.

IUCN/SSC Conservation Breeding Specialist Group (1996) Tamaraw Population and Habitat Viability Assessment Report (eds J. de Leon, N. Lawas, R. Escalada, P. Ong, R. Callo, S. Hedges et al.). IUCN/SSC Conservation Breeding Specialist Group, Apple Valley, USA.

Khatri, T.B., Shah, D.N. \& Mishra, N. (2012) Wild water buffalo Bubalus arnee in Koshi Tappu Wildlife Reserve, Nepal: status, population and conservation importance. Journal of Threatened Taxa, 4, 3294-3301.

Kuchai, J.A., Tak, H., Chishti, M.Z., Rasool, M., Dar, S.A. \& A Hm AD, J. (2011) Impact of season, sex, age, and agro-ecology on the prevalence of fascioliasis in buffalos of Ladakh. Online Journal of Animal and Feed Research, 1, 263-266.

Kuehn, D.W. (1976) Tamarao: endangered buffalo of the Philippines. National Parks and Conservation Magazine, 50, 18-20.

Kuehn, D.W. (1986) Population and social characteristics of the tamarao (Bubalus mindorensis). Biotropica, 18, 263-266.

MaAla, C.P. (2001) Endangered Philippine wildlife species with special reference to the Philippine eagle (Pithecophaga jefferyi) and tamaraw (Bubalus mindorensis). Journal of International Development and Cooperation, 8, 1-17.

Mace, G.M. \& Reynolds, J.D. (2001) Exploitation as a conservation issue. In Conservation of Exploited Species (eds J.D. Reynolds, G.M. Mace, K.H. Redford \& J.G. Robinson), pp. 4-15. Cambridge University Press, Cambridge, UK.

Manuel, G.C. (1957) Status of tamaraw, Anoa mindorensis (Heude). Proceedings of the Eight Pacific Scientific Congress, 3A, 1463-1474.

Matsubayashi, H., Boyles, R.M., Salac, R.L., Del Barrio, A.N., Cruz, L.C., Garcia, R.A. et al. (2010) Present status of tamaraw (Bubalus mindorensis) in Mt. Aruyan, Mindoro, Philippines. Tropics, 18, 167-170.

Momongan, V.G. \& WAlde, G.I. (1993) Behavior of the endangered tamaraw (Bubalus mindorensis Heude) in captivity. Asia Life Sciences, 2, 241-250.

Myers, N., Mittermeier, R.A., Mittermeier, C.G., DA FonsecA, G.A.B. \& Kent, J. (2000) Biodiversity hotspots for conservation priorities. Nature, 403, 853-858. 
Ong, P., Sarabia, A., Quimbo, M., Bravo, M., Rubio, R., TANAKA, K. et al. (1996) Population biology and simulation modeling. In Tamaraw Population and Habitat Viability Assessment Report (eds J. de Leon, N. Lawas, R. Escalada, P. Ong, R. Callo, S. Hedges et al.), pp. 51-79. Conservation Breeding Specialist Group/SSC/IUCN, Apple Valley, USA.

OWEN-Smith, N. (1993) Comparative mortality rates of male and female kudus: the costs of sexual size dimorphism. Journal of Animal Ecology, 62, 428-440.

Philippine Clearing House Mechanism (2012) Tamaraw Conservation Program. Http://www.chm.ph/index.php? option=com_content $\&$ view $=$ article $\& i d=283 \% 3$ Atamaraw conservation-program \&catid=87\&Itemid=90 [accessed 2 April 2014].

PrIMACK, R.B. (1993) Essentials of Conservation Biology. Sinauer Associates, Sunderland, USA.

REDFord, K.H. (1992) The empty forest. BioScience, 42, 412-422.

Ruckstuhl, K.E. \& Neuhaus, P. (2002) Sexual segregation in ungulates: a comparative test of three hypotheses. Biological Reviews, 77, 77-96.

SheIL, D. (2001) Conservation and biodiversity monitoring in the tropics: realities, priorities, and distractions. Conservation Biology, $15,1179-1182$.

Sinclair, A. (1977) The African Buffalo: A Study of Resource Limitations of Populations. University of Chicago Press, Chicago, USA.

Spinage, C.A. (1972) African ungulate life tables. Ecology, 53, $645-652$.

Steere, J.B. (1888) Letter to the secretary. Proceedings of the Zoological Society of London, 29, 413-415.
Suchomel, J. (2005) Some notes relating to the observation of tamaraw (Bubalus mindorensis) in Mt. Iglit-Baco National Park, the Philippines, in 2003. Lynx, New Series, 36, 103-110.

Talbot, L.M. \& Tацвот, M.H. (1966) The tamaraw (Bubalus mindorensis): observations and recommendations. Mammalia, 30, $1-12$.

Turner, W.C., Jolles, A.E. \& Owen-Smith, N. (2005) Alternating sexual segregation during the mating season by male African buffalo (Syncerus caffer). Journal of Zoology, 267, 291-299.

Van Vuren, D. \& Bray, M.P. (1986) Population dynamics of bison in the Henry mountains, Utah. Journal of Mammalogy, 67, 503-511.

WWF (2004) Counting Wildlife Manual. Mozambique Wildlife Management Series. WWW-Southern Africa Regional Office (SARPO), Harare, Zimbabwe.

\section{Biographical sketches}

SHINYA Is HIH AR A conducts non-invasive genetic analysis for wildlife conservation. RODEL BOYLES is interested in biodiversity, habitat-use and population dynamics. Hisashi MATSUBAYASH is a mammalogist and his research interests lie in conservation of wildlife and their habitats in tropical rainforests. ARNEL DEL BARRIO has conducted research on domestic buffaloes and is interested in tamaraw conservation. MERBEN CEBRIAN is interested in the sustainability of wildlife populations and the social-ecological landscape. Aıко ISHIDA specializes in animal nutrition, including that of wildife. Rosalina Lapitan is interested in the micronutrient content of wildlife diets. EUFROCINA ATABAY is interested in captive breeding with assisted-reproductive techniques. LIBERTADO CRUZ is interested in conserving animal genetic resources. YUKIO KANAI specializes in animal physiology and is interested in the science of sustainability. 